\title{
Editorial 13(1)
}

\section{Noella Edelmann}

ORCID Nr: 0000-0001-8386-9585

Department for E-Governance and Administration, Danube University Krems Noella.edelmann@donau-uni.ac.at

Welcome to issue 13(1) of the Journal of e-Democracy and Open Government.

This issue includes several different types of papers: conference papers, ongoing submissions and reflections.

Every year, JeDEM publishes some of the best papers from the IFIP EGOV1 and the CeDEM Asia conferences ${ }^{2}$. From the 2020 conferences, we publish 3 such articles in this issue. In the paper "How to Enable Collaboration in Open Government Data Ecosystems: A Public Platform Provider's Perspective", Johan Linaker and Per Runeson focus on how enabling collaboration in an Open Government Data (OGD) ecosystem. On the basis of the cases they analyse in their exploratory study, they suggest that public platform providers can help improve feedback loops, collaboration and achieve more demand-driven Open Government Data publication. Ahmed Kaharevic and Karin Skill, in their paper "Digital Citizenship in a Swedish Marginalised Neighbourhood"investigate digital citizenship and explore the differences between marginalised and hard to survey neighbourhoods and the national level in the context of public e-Health services provided in Sweden. The results show a low usage of the public e-Health services in Skäggetorp in comparison to other neighbourhoods in the region, making it important to raise questions about social rights, differences in terms of digital citizenship and eHealth services. The last conference paper, by Malika Toqmadi and Natalia Zakharchenko, "I Agree to Terms and Conditions: Negotiating Privacy Online in Central Asia" explores the formation of privacy as a value for different stakeholders in Kazakhstan and Kyrgyzstan. They point out that there are several challenges here, including cultural, political and the Soviet past that mean that privacy is not a priority topic in the digitalisation processes and is an issue that can be easily compromised by political turbulance and change.

The ongoing submissions address a range of topics central to the journal: usability in public participation, the institutionalisation of e-Democracy, activism, collaboration, the use of social media, information sharing and the role of leadership. Ivania Yoivanvic, Iñaki Goñi and Constanza Miranda, in "Remote Usability Assessment of Topic Visualization Interfaces with Public Participation Data: A

\footnotetext{
${ }^{1}$ https://dgsociety.org/egov-2021/

${ }^{2}$ https://digitalgovernment.wordpress.com/2019/08/30/cedemasia20/
} 
Case Study" consider how usability can be a key to issues such as transparency and accountability in citizen participation. Using an experimental design to examine user performance, they argue that public participation initiatives must think carefully about the interfaces used in public participation in order to ensure that the initiative is useful for the users involved. The article "The Institutionalization of e-Democracy: Challenges, Risks and Future Directions in an Indian Context", by Divya Kirti Gupta and Ashish Kumar Biswas, considers the need to "intertwine" democracy and e-democracy in order to address challenges and risks, and to successfully insitutionalise e-Democracy. They focus on India, which, they argue, is charactereised by dimensions such as the digital divide, a multitude of citizens' aspirations, and socio-cultural diversity. Nonetheless, the issues and concerns raised here are important for governments from countries around the world as they aim to implement e-Democracy solutions that are to increase trust and are able to support mechanisms and spaces that allow for a multitude of voices and opinions. Political expression is also central in the article "Bringing the Cross Pressures Thesis into the Digital Realm: Subjective Social Network Heterogeneity and Online Political Expression" by David Jenkins. Using data from Japan and South Korea, he investigates the relationship between users' subjective experiences (subjective social network heterogeneity) and political expression. Thus, he considers the effect of political cross-pressures not only in terms of the practical impact for democracy, but also theoretically, urging that this debate needs to consider the users' environments when they decide whether to engage in political expression on social media. In "Social News Use E Citizen Participation among Young Activists in Singapore", Winston Teo also considers engagement with social media content. Here, young activists were interviewed about how they understand social media as a source of news, what motivates them to use more than one social media platform and how this use fits into their political socialisation and mobilisation. Collaborative network settings are needed for efficient management of interagency information sharing, which, as Djoko Sigit Sayogo, J. Ramon Gil-Garcia and Sri Budi Cantika Yuli point out, are central to government efforts to develop and execute public policies that are smart, efficient, and more responsive to current social problems. In their article "Assessing the Role of Leadership Mechanisms for Inter-agency Collaboration and Information Sharing Success in Indonesia", they argue that information sharing relies on formal and informal leadership and highlighting the implications for practice such as the need to ensure executive invovlement in information sharing projects.

This issues concludes with the reflection "Machine learning in Governments: Benefits, Challenges and Future Directions" by Yulu Pi. It reviews the literature on the use of machine learning by government, aiming to identify the benefits and challenges of wider adoption of machine learning applications in the public sector and proposes some ideas and directions for future research.

We hope that you will consider contributing your future research to JeDEM too, and, in the meantime, enjoy reading this issue! 